\title{
NARRATIVA Y REPRESENTACIÓN ICÓNICA. ¿QUÉ NOS CUENTAN LAS IMÁGENES? \\ LA ÉPOCA DE LA CONTRARREFORMA EN ESPAÑA COMO EJEMPLO
}

\author{
Narrative and Iconic Representation: What do Images Tell Us? \\ Counter-reformation in Spain as an Example \\ María del Mar Ramírez Alvarado (Universidad de Sevilla) \\ http://dx.doi.org/10.12795/AdMIRA.2009.01.02
}

Resumen. El presente artículo tiene como objetivo profundizar en las reflexiones que, sobre las imágenes como modelos de representación, se desarrollaron en España a lo largo del siglo XVI y principios del XVII y se editaron en pequeñas obras de poca circulación. Con el cisma religioso que llevó a la consolidación del Protestantismo, la veneración de imágenes sagradas será considerada un acto de idolatría. De esta disputa salieron a la luz interesantes planteamientos enmarcados en el espíritu de la Contrarreforma y del Concilio de Trento sobre el valor de las imágenes de culto para el fomento de la espiritualidad y de la creencia en la divina providencia, así como la finalidad moralizante de la representación artística. Las imágenes sagradas tenían una historia que contar, y esa historia llevaba a Dios.

Palabras clave. Reforma - Contrarreforma - Imagen - Concilio de Trento Renacimiento

\begin{abstract}
This article aims at deepening reflections that, on images as representation models, took place in Spain throughout the 16th century, and got into print as lowcirculation, small works. After the religious schism that led to the consolidation of Protestantism, veneration of images was regarded as an act of idolatry. From this dispute, interesting proposals came to light, within the framework of the CounterReformation spirit and The Council of Trent, on the value of cult images to foster both spirituality and belief in the Divine Providence, as well as the moralizing purpose of artistic representation. Sacred images had a story to tell, and that story led to God.
\end{abstract}

Keywords. Reformation - Counter-Reformation - Image - Council of Trent Renaissance

"El rústico y otros hombres ydiotas, y los mudos, ¿como se acordarían de Dios y de sus santos, sino viessen pintadas sus imágenes e historias en los templos?"

San Gregorio Magno 


\section{INTRODUCCIÓN}

El objetivo del trabajo que se presenta a continuación es el de profundizar en las reflexiones que, sobre las imágenes como modelos de representación, se desarrollaron en España en los primeros años de la modernidad. Éste es un período muy importante en la historia de la comunicación y de la imagen porque en él coinciden dos elementos que definen dichas reflexiones. Por una parte, el afianzamiento de las nociones sobre la perspectiva artificial propuestas por los artistas del Renacimiento a lo largo del Quattrocento. Por otra, el cisma religioso que condujo a la consolidación del Protestantismo y, por ende, a una importante ruptura con la Iglesia de Roma. Uno de los aspectos más controvertidos tenía que ver con la veneración de imágenes de Santos y de la Virgen en sus distintas advocaciones, que Martín Lutero y sus seguidores consideraron actos censurables de idolatría.

Precisamente de esta disputa salieron a la luz interesantes planteamientos sobre las propiedades de las imágenes en otros terrenos distintos al del propio disfrute estético que son los que fundamentalmente se mencionarán en este trabajo. También se debatirá sobre el valor de las imágenes de culto para el fomento de la espiritualidad así como la finalidad moralizante de la representación artística. Como metodología se ha seguido la recopilación y análisis de pequeños opúsculos y tratados de arte de poca circulación editados en España a lo largo del XVI y principios del XVII. Todos dan cuenta de las ideas típicas de la Contrarreforma en lo que se refiere a las imágenes como instrumentos de edificación espiritual.

\section{Contextualización}

El Renacimiento fue una época de la historia caracterizada por el interés de los artistas por representar la realidad de la forma más parecida al natural. En este intento no sólo había que conformarse con la reproducción de la naturaleza de la manera más adecuada sino que, además, era necesario procurar que la simple verdad natural fuese lo más hermosa posible. Esta bella invenzione o belleza añadida fruto del equilibrio de colores, formas y proporciones, no debía circunscribirse exclusivamente a las habilidades y recursos expresivos del artista. Las leyes de la geometría y de las matemáticas, condensadas en los principios de la perspectiva artificial, funcionaron entonces como soporte de la reproducción del volumen de los elementos y como guías para la construcción del espacio. Jacques Aumont, en su obra La imagen, señala que:

La perspectiva es una transformación geométrica que consiste en proyectar el espacio tridimensional sobre un espacio bidimensional (una superficie plana) según ciertas reglas y de modo que transmita, en la proyección, una buena información sobre el espacio proyectado; idealmente, una proyección perspectiva debe permitir la reconstrucción mental de los volúmenes proyectados $\mathrm{y}$ de su disposición en el espacio (Aumont: 1992: 224).

Escribiría Leonardo Da Vinci al respecto: "La pintura más digna de alabanza es la que se asemeja más a la cosa imitada". También Giorgio Vasari y otros autores del Renacimiento considerarán que la perfección en el arte se encontraba estrechamente vinculada al concepto de mímesis.

Es así como muchos de los artistas de la época, en ese intento por conferir "cientificidad" a sus reflexiones en el terrero de las artes, consignan sus indagaciones en tratados y escritos diversos. Con la acentuada proliferación de estos tratados, surgidos al amparo de 
la idea corporativa de que el arte debía ser aprendido y enseñado, se buscaba, asimismo, establecer un corpus teórico-conceptual que regulara la actividad artística. Una de las características más importantes del Renacimiento fue, precisamente, esta gran voluntad y capacidad para teorizar en relación a las experiencias plásticas del momento. La revisión de tales estudios constituye una tarea de primer orden para comprender las formas y estilos de representación en Europa a lo largo del siglo XVI.

Aunque en España se retrasa un poco la introducción de las ideas del Renacimiento italiano, poco a poco se va advirtiendo un cierto cambio en los esquemas compositivos y de representación. Es durante el siglo XVI y, sobre todo, a lo largo de las primeras décadas del XVII, cuando la evolución de un arte con características propias (aunque notablemente influenciado por los movimientos artísticos de Italia y Flandes) cristalizaría en la producción de un corpus teórico de valor para comprender los modelos de representación icónica de este momento histórico ${ }^{1}$.

A su vez, precisamente en un período tan intenso como el del Cinquecento y también en Europa, se produce un importante giro cuyo epicentro estuvo en los movimientos religiosos reformistas y contrarreformistas que generaron profundas trasformaciones desde las primeras décadas del XVI. La necesidad de cambio que se encontraba latente frente al abuso de poder eclesiástico, al comportamiento simoníaco y al incremento de la riqueza del clero, cristaliza en la revisión de los dogmas de la Iglesia, iniciada desde su mismo seno por el monje agustino Martín Lutero. En la ciudad alemana de Wittenberg, en 1517, Lutero elabora sus famosas 95 tesis que repudiaban los abusos y pretensiones eclesiásticas $^{2}$. El documento se fijó en las puertas de la catedral de la localidad, lo que según las costumbres académicas del momento significaba que quedaba abierto el debate público.

La difusión y resonancia de las tesis resultó sorprendente debido a que estos hechos coinciden con otro cambio importante en la historia de la comunicación: la invención y expansión de la imprenta también en Alemania, hecho este que revolucionó las formas de acopio y difusión del conocimiento y que democratizó el consumo y acceso a la información. Ya desde finales del siglo XV las principales ciudades Europeas contaban con talleres de impresión. Se estima que en 1470 había doce lugares que contaban con imprenta. Éste número ascendía a ciento diez en 1489 y, a finales de siglo, se calculan más de doscientos lugares en los que funcionaban talleres de impresión (Martínez de Sousa, 1981: 134).También puede mencionarse el desarrollo de las técnicas de la xilografía aplicadas a la impresión que permitieron que las imágenes impresas se difundieran de una forma más rápida y generalizada. El grabado representó la posibilidad

\footnotetext{
${ }^{1}$ Jonathan Brown, en su obra La Edad de Oro de la pintura en España (1990: 21) establece tres fases estilísticas en la pintura española dentro del lapso comprendido entre finales del siglo XV y finales del XVII. La primera de ellas, de gran complejidad y en la que los pintores españoles se enfrentan a las novedades procedentes de Italia y de los Países Bajos, culmina en torno a 1555. Se inicia entonces la segunda fase, situada con exactitud cuando en 1556 asciende Felipe II al poder. Este monarca se convirtió en un gran promotor del arte, consolidó el papel de la Corona como monopolizadora del mecenazgo artístico y sentó las bases para la época del esplendor de la pintura española del XVII que comenzaría a desarrollarse durante el reinado de su hijo Felipe III (momento en el cual, precisamente, se escriben muchos de los tratados de arte del Siglo de Oro). La tercera etapa, se inicia con el reinado de Felipe IV y se extiende por el resto de la centuria. ${ }^{2}$ Estas tesis alcanzaron un mayor desarrollo en una obra de Martín Lutero publicada al año siguiente, en 1518, titulada Tratado sobre la indulgencia y la gracia.
} 
de que las estampas se transformasen en vehículos del saber y la cultura accesibles a todos los grupos sociales.

Bajo estas circunstancias las obras de Lutero "casi enseguida fueron impresas y circularon velozmente por toda Europa, convirtiéndose así la imprenta en un instrumento bastante imparcial de divulgación, ya que las tesis se multiplicaron con tanta rapidez como las indulgencias" (Bowen, 1979: 384). Rápidamente la Reforma encuentra adeptos entre doctas personalidades, ciudadanos importantes y príncipes.

Después de terribles enfrentamientos, el Emperador Carlos V se ve obligado a firmar la Paz de Habsburgo en 1555, en la cual se decretaba la soberanía religiosa de los Estados. Finalmente, el continente europeo quedaría escindido en dos bandos: los reformistas y los que, a través de la Contrarreforma, intentaron restaurar el poderío de la Iglesia y del Papado.

\section{Función "didáctica" de las imágenes sagradas}

En una España esencialmente contrarreformista, la preocupación religiosa por el origen y función de las imágenes es la que domina en gran medida la reflexión teórica sobre la representación. Sobre todo en el terreno de la pintura, se discute con fruición la finalidad moralizante del arte. También abundan los tratados apologéticos que abordan el tema de la nobleza y carácter liberal de las artes. Aunque mantienen sus características propias, estos escritos, alimentados por las obras de los grandes tratadistas italianos, evidencian el conocimiento y manejo de las principales aportaciones del Renacimiento.

A partir de la Reforma Protestante el problema de la imagen adquirió entonces una nueva dimensión. El adorar y transformar en figuras santas las creaciones humanas se convirtió en anatema: "No haréis para vosotros ídolos, ni escultura, ni os levantaréis estatua, ni pondréis en vuestra tierra piedra pintada para inclinaros a ella" (Levítico, 26:1) ${ }^{3}$. Estas ideas se extendieron por Europa, ganando rápidamente apoyos en distintos sectores de la sociedad.

La respuesta tardó algunas décadas, pero tuvo también un gran alcance. En este marco, el Concilio de la Reforma Católica, reunido en la ciudad de Trento, ocupó uno de sus capítulos más importantes (precisamente la última de sus sesiones del 3 y 4 de diciembre de 1563) a la discusión del tema de las imágenes. Esta fuerte disputa sobre las imágenes reproduciría la que había lugar también en el segundo Concilio de Nicea, en el año 787. En ese entonces dos grupos se encontraban enfrentados en el mundo bizantino: los enemigos de las imágenes (conocidos como iconoclastas o iconomacos) y los partidarios de las mismas (iconófilos o iconódulos). Finalmente se decreta que rechazar la veneración de imágenes llevaría a negar la encarnación del Verbo de Dios ya que el homenaje rendido al ícono iba directamente al prototipo... per visibilia ad invisibilia (Debray, 1994: 69-70).

En primer término, el Concilio de Trento enfrentaría la posición radical de los iconoclastas protestantes condenando de forma contundente su actitud de irreverencia e irrespeto hacia las imágenes sagradas: "quienes afirman que no hay que venerar ni honrar las reliquias de los santos, o que su veneración y la de otros sagrados monumentos es

\footnotetext{
${ }^{3}$ En los escritos reformistas del momento aparecen aludidos, de forma reiterada, pasajes bíblicos diversos del Antiguo y del Nuevo Testamento que condenaban la idolatría: $1^{a}$ Carta a los Corintios, 8:4, 8:10, 10:28, 12:2, $1^{a}$ Carta a los Tesalonicenses 1:9, $1^{a}$ carta de Juan 5:21, Apocalipsis 2:14.
} 
inútil [...], deben ser totalmente condenados". (Garriga, 1983: 346) 4

En segundo lugar, el Concilio tridentino puso en tela de juicio la actitud de algunos prelados de la Iglesia y de una proporción importante del pueblo católico, cuya desmedida adoración y culto hacia las imágenes rozaba la paganismo. Por consiguiente, se aconseja la erradicación de toda superstición en el "uso sagrado de las imágenes". Las imágenes de Jesucristo, de la Virgen Madre de Dios y de los santos de la Iglesia debían ser expuestas sólo para que se les tributara la veneración y el honor debidos:

...pero no es que deban ser honradas por la creencia de que reside en ellas alguna divinidad o poder, o porque haya que pedirles algo o depositar en ellas la confianza, como antaño hacían los gentiles, que fundaban su esperanza en los ídolos: sino porque el honor que se tributa a las imágenes va dirigido a los prototipos que ellas representan, de tal modo que, a través de las imágenes [...] adoramos a Jesucristo y veneramos a los santos cuya semejanza representan (Garriga, 1983: 347).

En último lugar, el sínodo condena abiertamente la paganización enraizada en las corrientes humanistas y clasicistas que promovieron la mundana admiración por una iconografía plagada de desnudos, de escenas mitológicas y de imágenes "impúdicas" las cuales, incluso, llegaban a exhibirse en las iglesias (fue famosa la polémica sobre "El Juicio Final", mural realizado al fresco por Miguel Ángel para decorar el ábside de la Capilla Sixtina). Puesto que en la casa de Dios convenía la santidad, no debía entrar en ella nada profano o deshonesto. Era necesario evitar entonces "toda lascivia, de modo que no se pinten ni adornen imágenes de belleza provocativa".

En conclusión, el Concilio de Trento reafirma la función "didáctica" de las imágenes sagradas: a través de los misterios expresados por medio de pinturas y otras representaciones el pueblo podía ser ilustrado en la conmemoración de los artículos de la fe y en la comprensión de los milagros realizados por Dios a través de sus santos. El Consejo tridentino fue rotundo en cuanto a sus conclusiones considerando que si alguien enseñara o creyere algo contrario a estos decretos debía ser excomulgado.

En consecuencia, son los temas religiosos los que vienen a ocupar un lugar preponderante en la creación artística. Se repite el tema de la visión del Todopoderoso y de Cristo en majestad, típico de las ilustraciones medievales. Además, son frecuentes los temas bíblicos, la vida de Jesús y de los santos, la imagen de la Virgen y el Niño. En la iconografía de Jesús se evitan los temas sangrientos, por lo que se recurre a la figura del Niño Jesús y a la imagen del Cristo triunfante resucitado. Se representa con frecuencia a la Virgen y son muchas las advocaciones que se le conceden. Asimismo, se extiende la representación alegórica, es decir, la representación (tipificada a través de atributos especiales o de una apariencia corporal determinada) de cualidades que en sí mismas carecen de entidad propia.

A efectos de este artículo mencionaremos las principales aportaciones teóricas de este momento de la historia, comenzando por los tratados de arte que difundieron las ideas de la contrarreforma con autores como Gaspar Gutiérrez de los Ríos y Alonso de Butrón, entre otros que plasmaron sus ideas en pequeñas obras de no mucha circulación que tenían por objetivo primordial la defensa del arte de la pintura, no sólo como tarea manual,

\footnotetext{
${ }^{4}$ El texto se encuentra en el "Decreto sobre la invocación, la veneración y las reliquias de los santos y sobre las imágenes sagradas" recogido por Joaquín Garriga en su obra Renacimiento en Europa. Pueden consultarse las resoluciones del Concilio tridentino en: PALEOTTO, Cardinale Gabriele (1842): Acta Concilii Tridentini, Anno MDLXII. et MDLXIII. Londres: Jacobum Duncan.
} 
sino como trabajo intelectual.

\section{Imágenes para el crecimiento espiritual: las ideas de la Contrarreforma en el terreno de la representación artística.}

El clima de oposición a las ideas luteranas determinará firmemente la concepción de toda una tratadística contrarreformista inspirada en los preceptos tridentinos. En España, esta corriente teórica en el campo de la representación artística floreció en lo que se conoce como el Siglo de Oro de la pintura española, momento en el que circularon textos diversos, algunos pequeños y poco conocidos, y otros de más repercusión como el Tratado de la Pintura de Francisco Pacheco. En estas obras, además de la reflexión sobre el valor religioso de las imágenes, se aprecia igualmente la comprensión de los principales postulados del Renacimiento italiano.

Uno de estos teóricos de la pintura española del Siglo de Oro fue Gaspar Gutiérrez de los Ríos. Poco se conoce de su biografía, salvo los datos que aparecieron en la portada de su Noticia general para la estimación de las artes. En este estudio, editado en Madrid por Pedro Madrigal en 1600, se describía a su autor como "profesor de ambos derechos y letras humanas, natural de la ciudad de Salamanca" (Gutiérrez de los Ríos, 1600: 167$168)^{5}$.

El objetivo básico de esta obra consistía en ofrecer argumentos que sustentasen la idea de la liberalidad de las artes. Para ello, el autor elabora una compleja disertación repleta de minuciosas comparaciones entre actividades y oficios diversos tan dispares como la medicina, arquitectura, retórica, agricultura, ejercicios de guerra, tapicería, bordado, astrología, historia, música y geometría (además de las artes), entre otras.

La difusión de la historia por medio de la pintura y de la escultura, que superaba con creces las posibilidades narrativas de la escritura, debía ser aprovechada en el terreno del crecimiento espiritual ya que la representación artística era cosa de "verdades y eternas". El siguiente razonamiento de Gutiérrez de los Ríos, como hombre del siglo XVI, resulta interesante en relación a la importancia de la imagen en comprensión de los hechos históricos, aspecto éste de fundamental relevancia en la presente investigación:

El leer cría melancolía y casa [cansa]. El ver, y particularmente en estas artes, nunca se harta. Demás desto, quié duda, sino q' la historia, aunque sea elocuentemente dicha, no es de tato [tanto] gusto y alegría como las q' están bien pintadas y relevadas. Con las bien pintadas y relevadas se deleytan los ojos, se recrea la memoria, se aguza y abiva el entendimiento, se apacienta el ánimo, se incita la voluntad, y se está finalmente encendiendo el deseo (Gutiérrez de los Ríos, 1600: 171).

Estos escritos están fuertemente impregnados por el espíritu tridentino del momento. El dibujo, a través de cual se eternizaba la memoria de las cosas, tiene un claro origen religioso y un fin absolutamente espiritual: "El rústico y otros hombres ydiotas, y los mudos, como se acordarían de Dios y de sus santos, sino viessen pintadas sus imágenes e

\footnotetext{
${ }^{5}$ Los textos de Gaspar Gutiérrez de Los Ríos han sido extraídos directamente de la primera edición impresa de su obra que se encuentra en la Biblioteca Nacional de Madrid. Gutiérrez de los Ríos, Gaspar (1600): Noticia general para la estimación de las artes, y de la manera en que se conocen las liberales de las que son mecánicas y serviles, con una exhortación a la honra de la virtud y del trabajo contra los ociosos, y otras particulares para las personas de todos estados. Madrid: Pedro Madrigal.
} 
historias en los templos?"' . Tal afirmación, que repetirán hasta la saciedad los tratadistas de la Contrarreforma, proviene de una epístola del Papa San Gregorio Magno, quien vivió entre los años 540 y 604 d.C (Barash, 1994: 63-64). Dicha carta fue enviada por Gregorio Magno a un obispo de Marsella con tendencias iconoclastas que había admitido la destrucción de imágenes de devoción. En la misma, las imágenes eran defendidas por el pontífice, más que por su significado espiritual, por su utilidad en la instrucción de los iletrados.

En una pequeña obra anónima editada en 1619, titulada Memorial de los pintores de la corte a Felipe III sobre la creación de una academia o escuela de dibujo, aparece citada una anécdota (Calvo Serraller, 1991: 165) de Gregorio Magno según la cual, habiendo leído en repetidas ocasiones un conmovedor relato, no lloró sino cuando lo vio representado en una imagen. Al parecer, San Gregorio hizo pintar en diversas iglesias escenas de los evangelios para que socorriesen la ignorancia, la falta de entendimiento y la flaqueza humana de manera más efectiva que la lectura. Al igual que Gaspar Gutiérrez, los pintores de la Corte de Felipe III esgrimen en su Memorial el señalado planteamiento de San Gregorio que tanto éxito tuvo entre los contrarreformistas:

Los pintores de esta corte dicen, que cuán necesaria e importante sea la facultad y arte de la pintura, para la noticia, reverencia y alabanza de Dios, y de sus santos, para los heroicos y divinos milagros [...] Nuestra madre la Iglesia por este medio, como por lenguaje común y claro, y como por libro abierto se declara y da a entender más claramente, en especial a mujeres y gente idiota que no saben, o no pueden leer (Butrón, 1626: 1 verso) ${ }^{7}$.

Desde casi dos siglos atrás, en los tratados italianos podían leerse las reflexiones sobre el desarrollo de la técnica de la perspectiva que permitía la representación de la naturaleza de la manera más parecida al elemento representado. El abogado del Consejo de Castilla Juan de Butrón, en un tratado publicado en el año 1626 que llevaba por título Discursos apologéticos en que se defiende la ingenuidad del arte de la pintura, propone una definición del arte de la pintura en íntima relación a las posibilidades del trazo en perspectiva y de imitación de la naturaleza:

La pintura, según la mejor definición [...] es un remedo de las obras de Dios, y una emulación de la naturaleza; pues no se halla cosa que aquélla críe, a la que ésta no copie y felecissimamente la perpetúe. La superioridad deste Arte con las sombras, y relieves de que se ayuda engaña la vista de manera, que lo llano de la tabla o lienzo milagrosamente representa y pinta lo cóncavo y relevado del objeto, los claros y oscuros, lo fuerte y lo suave de la más sutil sombra (en Calvo Serraller, 1991: 241) ${ }^{8}$.

6 "Aliud est picturam adorare, aliud per picturae historiam quid sit adorandum addiscere. Nam quod legentibus scriptura, hoc idiotis cernentibus praestat pictura; quia in ipsa legunt qui litteras nesciunt" es la frase en latin de San Gregorio Magno incluida en la "Epistulae ad Serenum Massilensem episcopum" (citada en Calvo Serraller, 1991: 165). Aunque este pensamiento tuvo seguidores durante la Edad Media, algunos de los más famosos enciclopedistas medievales, como por ejemplo Rabano Mauro, insisten de la superioridad de la escritura sobre la pintura.

${ }^{7}$ La obra de Juan de Butrón se titula Discursos apologéticos en que se defiende la ingenuidad del arte de la pintura. Que es liberal y noble de todos los derechos, no inferior a las siete que comunmente se reciben. Hemos consultado directamente la edición de 1626 en la Biblioteca Nacional en Madrid.

${ }^{8} \mathrm{El}$ texto se titula Copia de los pareceres y censuras de los reverendíssimos padres 
En el año 1629 se publicó en Madrid el Memorial informatorio por los pintores. En el pleito que tratan con el señor de su Magestad, en el Real Consejo de Hazienda, sobre la exempción del arte de la pintura, suscrito por los principales hombres de letras del momento en defensa de la exención fiscal de la pintura. Entre los firmantes se encontraba, por ejemplo, Lope de Vega, quien señala que no era necesario poner en duda el ser del arte de la pintura ni "pagar alcabal" por la misma, ya que "las Pinturas de las imágenes eran como historia, y escritura para los que ignoran".

En el prólogo de este curioso folleto, que recoge las opiniones de diversos catedráticos de las Universidades de Salamanca y de Alcalá de Henares acerca de la moralidad en el arte, se pone en boca de Lope de Vega las siguientes palabras que describen las imágenes: son..."personages propios de representación natural, que no hazen número con el original que retratan; antes de ordinario le representan con mayor viveza. [...] Son despertadores perpetuos de la memoria: engendran con grande eficacia efectos proporcionados con el objeto que proponen" (VV.AA., 1626: 165 recto).

También en dicho memorial escribe Antonio de León, en aquel momento Relator de Supremo Consejo de Indias. Pero de todos, quizás el texto que resulte más interesante es el aportado por Fray José de Valdivieso "En gracia del arte noble de la pintura", cuyas reflexiones aparecen escondidas en un mar de diatribas de carácter jurídico-fiscal. Para Valdivieso, figura e imagen son conceptos inherentes al arte de la representación "porque el Padre Eterno mirándose como en un espejo purísimo y cristalino: Speculum sine macula, engendra una figura, e imagen viva sustancial, perfectísimamente natural, retrato de su gloria" (VV.AA, 1626: 182 verso).

En la misma línea que muchos pensadores de su época influenciados de manera directa por las ideas de la Contrarreforma, este autor considera que la pintura es mucho más efectiva que la escritura "por la persuasión eficaz de la vista, el más imperioso de los sentidos, y el que más despierta al alma con las imágenes, que son predicadores mudos, y torcedores elocuentes" (Fernández Arenas, 1982: 26).

\section{Conclusiones}

La vorágine creadora del Renacimiento produjo en Europa una importante ruptura con las representaciones medievales del mundo visible: el artista debía perseguir la imitación de lo real. Para ello, aparte de poseer talento creador, era necesario conocer los principios de la perspectiva artificial nutridos de nociones provenientes de las matemáticas y de la geometría. Desde entonces estos principios sirvieron como guías para la reconstrucción, en la superficie pictórica objetivamente bidimensional, de un plano figurativo en el que el espacio se presentaba homogéneo y unitariamente estructurado.

Como fruto de las convenciones históricas y culturales, a partir del siglo XV la perspectiva artificial se convirtió en el modelo referencial de las representaciones icónicas de la modernidad. La búsqueda de realismo en el Renacimiento desembocó en una representación con un alto grado de iconicidad. En consecuencia, a partir de entonces se asumió la figuración realista prácticamente como el único sistema de representación posible, ya que se hizo una equivalencia entre la figuración y la percepción natural de los objetos. A través de la representación debía conseguirse la imitación de la realidad de

maestros y señores catedráticos de las insignes universidades de Salamanca, y de Alcalá, $y$ de otras personas doctas. Sobre el abuso de las figuras, y pinturas lascivas y deshonestas, que se muestra, que es pecado mortal pintarlas, esculpirlas y tenerlas patentes donde sean vistas. 
forma que "los ojos humanos resultan engañados" (como se señala en muchos tratados). La pintura más perfecta era aquella que lograba engañar al espectador "haciendo pasar por realidad lo que es ficción".

Una de las características del Renacimiento fue ese empeño y capacidad para teorizar en relación a las experiencias plásticas del momento. Muchos tratados de arte de los siglos XV y XVI coinciden en tratar diversos temas, que van cambiando sus matices con el paso del tiempo: el estudio de la naturaleza, la preocupación por la justa medida, la recuperación del arte antiguo y de las formas clásicas, la discusión sobre el paragone de las artes, etc.

A lo largo del siglo XVI se produce en Europa un importante cisma religioso a raíz de las ideas de Martin Lutero que repercute en todos los ámbitos de la vida, incluyendo el de la representación artística. El ambiente de pugnas religiosas del momento determina, sobre todo en España, una interesante reflexión teórica sobre la representación icónica inspirada en la atmósfera de la Contrarreforma y en los preceptos del Concilio de Trento. Los aspectos vinculados a la finalidad moralizante de la representación, a la nobleza y carácter liberal de las artes y, sobre todo, al valor de las imágenes de culto que fomentaban la espiritualidad y la creencia en Dios, constituyen los puntos ejes de muchos escritos teóricos.

Con el movimiento protestante y las reacciones contrarreformistas, la literatura artística adquiere nuevos matices: se profundiza en la función de la imagen, concebida como elemento de conducción hacia lo divino (que fortalece la fe en lo que no se ve) o, en su revés, como instrumento de adoración idolátrica. Además, se debate intensamente el carácter sagrado o profano de la representación artística, se plantea la necesidad de espiritualizar la representación de la naturaleza y se despierta un nuevo interés por el estudio iconográfico. Ya a finales de siglo, el manierismo marcaría el retorno a los principios, a la formación específica, a la práctica del artista controlada por un cuerpo teórico racional.

\section{Referencias bibliográficas}

Arfe y Villafañe, Juan (1585): De varia commesuracion para la esculptura y architectura. Sevilla, Andrea Pescioni y Juan de León (según la edición facsimilar editada por Valencia: Albatros, 1979).

Aumont, Jacques (1992): La imagen. Barcelona: Paidós.

Barasch, Moshe (1978): Light and Color in the Italian Renaissance Theory of Art. New York, New York University Press.

(1994) Teorías del arte. De Platón a Winckelmann. Madrid: Alianza.

Bowen, James (1979): Historia de la educación occidental. La civilización de Europa siglos VI-XVI. Barcelona: Herder.

Brown, Jonathan (1990): La Edad de Oro de la pintura en España. Madrid: Ed. Nerea.

Butrón, Juan de (1626): Discursos apologéticos en que se defiende la ingenuidad del arte de la pintura. Que es liberal y noble de todos los derechos, no inferior a las siete que comúnmente se reciben. Madrid: Luis Sánchez.

Calvo Serraller, Francisco (ed.) (1991): Teoría de la pintura del Siglo de Oro. Madrid: Cátedra.

CÉSPEDES, Pablo de (1604): Discurso de comparación de la antigua y moderna pintura. Córdoba: s.e.

Chastel, André (1966): El gran taller de Italia: 1460-1500. Madrid, Aguilar.

(1968): La crisis del Renacimiento: 1520-1600. Barcelona: Carroggio. 
(1982): Arte y humanismo en Florencia en tiempos de Lorenzo el Magnífico. Madrid: Cátedra.

(1988): El arte italiano. Madrid: Akal.

Debray, Régis (1994): Vida y muerte de la imagen. Historia de la mirada en Occidente. Barcelona: Paidós.

Fernández Arenas, José (ed.) (1982): Renacimiento y Barroco en España. Colección Fuentes y Documentos para la Historia del Arte, vol. VI. Barcelona: Gustavo Gili.

Francastel, Pierre (1969): La figura y el lugar. El orden visual del Quattrocento. Caracas: Monte Avila Editores.

(1984a): Pintura y sociedad. Madrid: Cátedra, 1984.

(1984b): Sociología del arte. Madrid: Alianza, 1984.

(1990): La realidad figurativa. Barcelona: Paidós, 1990.

Garriga, Joaquim (ed.) (1983): Renacimiento en Europa. Colección Fuentes y Documentos para la Historia del Arte, vol. IV. Barcelona: Gustavo Gili.

Gutiérrez de los Ríos, Gaspar (1600): Noticia general para la estimación de las artes, y de la manera en que se conocen las liberales de las que son mecánicas y serviles, con una exhortación a la honra de la virtud y del trabajo contra los ociosos, y otras particulares para las personas de todos estados. Madrid: Pedro Madrigal.

Lope de Vega (1626): "Dicho y deposición de Frei Lope Felix de Vega Carpio, del Abiro de San Juan, celebrado en el mundo a por su ingenio, que está en los autos de esta causa". En: Memorial informatorio por los pintores. En el pleito que tratan con el señor de su Magestad, en el Real Consejo de Hazienda, sobre la exempción del arte de la pintura. Madrid: Luis Sánchez.

Lutero, Martín (1977): Obras. Salamanca: Ed. Sígueme.

MARTÍNEZ DE SOUSA, José (1992): Pequeña historia del libro. Barcelona: Labor.

Menéndez y Pelayo, M. (1974): Historia de las ideas estéticas en España. Madrid: CSIC. PACHECO, Francisco (1990): El arte de la pintura. Madrid: Cátedra.

Sagredo, Diego de (1976): Medidas del romano: necesarias a los oficiales que quieren seguir las formaciones de Basas, Columnas, Capiteles y otras pieças de los edificios antiguos. Valencia: Ed. Albatros.

(1986): Medidas del romano. Madrid: Instituto de Conservación y Restauración de Bienes Culturales/Colegios Oficiales de Aparejadores y Arquitectos técnicos.

Schlosser, Julius (1976): La literatura artística. Madrid: Cátedra.

Vitruvio (1995): Los diez libros de arquitectura. Barcelona: Iberia.

VV.AA. (1626): Memorial informatorio por los pintores. En el pleito que tratan con el señor de su Magestad, en el Real Consejo de Hazienda, sobre la exempción del arte de la pintura. Madrid: Luis Sánchez. 